\title{
A TRANSEXUALIDADE E A GRAMÁTICA NORMATIVA DO SISTEMA SEXO-GÉNERO
}

Márcia Arán

Psicanalista; professora visitante do Instituto de Medicina Social da Uerj; membro do Espaço Brasileiro de Estudos Psicanalíticos.

RESUMO: Este trabalho tem como objetivo analisar o discurso sobre a transexualidade na psiquiatria e na psicanálise. Em linhas gerais, o transexualismo é considerado uma patologia por ser definido como um "transtorno de identidade", dada a não-conformidade entre sexo e gênero. Por outro lado, ele também pode ser considerado uma psicose graças à suposta recusa da diferença sexual. O que define este diagnóstico é uma concepção normativa dos sistemas de sexo-gênero, a qual se converte em um sistema regulador da sexualidade. Discutem-se as possibilidades de uma reflexão crítica na psicanálise que permita o descolamento da transexualidade deste território normativo da patologização.

Palavras-chave: Transexualidade, subjetividade, sexo, gênero, psicanálise.

ABSTRACT: Transsexuality and normative grammar of the sex-gender systems. The objective of this paper is to analyze the transsexual in psychiatry and partly in psychoanalysis. It can be observed that transsexual is referred to as pathology being that it is considered an "identity disorder", given the non-conformity between sex and gender. On the other hand, it can also be considered a psychosis owing to the refusal of sexual difference. What defines the diagnosis of transsexual is a normative conception of the gender-sex systems, which is converted onto a regulating system of sexuality. In spite of the complexity of this issue, this paper discusses the possibilities of a critical reflection in psychoanalyze that allows for the detachment of transsexuality in this normative territory of pathologization.

Keywords: Transsexuality, subjectivity, sex, gender, psychoanalysis. 
A transexualidade é considerada um fenômeno complexo. Em linhas gerais, caracteriza-se pelo sentimento intenso de não-pertencimento ao sexo anatômico, sem a manifestação de distúrbios delirantes e sem bases orgânicas (como o hermafroditismo ou qualquer outra anomalia endócrina) (CASTEL, 2001, p.77). Pode-se dizer que a fundamentação deste fenômeno na atualidade está baseada em dois dispositivos distintos. O primeiro diz respeito ao avanço da biomedicina na segunda metade do século passado - principalmente no que se refere ao aprimoramento das técnicas cirúrgicas e ao progresso da terapia hormonal - que faz do desejo de “adequação" sexual uma possibilidade concreta. O segundo concerne à forte influência da sexologia na construção da noção de "identidade de gênero" como sendo uma "construção sociocultural", independente do sexo natural ou biológico.

Nas diversas teorias que abordam esta questão parece haver um aspecto consensual: o de que na transexualidade haveria uma incoerência entre sexo e gênero. $O$ discurso atual sobre o transexualismo na sexologia, na psiquiatria e em parte na psicanálise faz desta experiência uma patologia - um "transtorno de identidade" - dada a não-conformidade entre sexo biológico e gênero. Por outro lado, ele também pode ser considerado uma psicose devido à recusa da diferença sexual — leia-se, da castração dita simbólica. Nota-se que nestas teorias, o que define o diagnóstico de transexualismo é uma concepção normativa seja dos sistemas de sexo-gênero, seja do dispositivo "diferença sexual”. ${ }^{1}$ Ambas estão fundadas numa matriz binária heterossexual que se converte em sistema regulador da sexualidade e da subjetividade.

Nesta gramática, gêneros inteligíveis são aqueles que mantêm uma continuidade entre sexo, gênero, práticas sexuais e desejo, por intermédio dos quais a identidade é reconhecida e adquire um efeito de substância. Os espectros de descontinuidade e incoerência que se transformam numa patologia são, desta forma, apenas concebíveis em função deste sistema normativo. Neste sentido, “certos tipos de identidade de gênero parecem ser meras falhas do desenvolvimento ou impossibilidades lógicas, precisamente porque não se conformam às normas de inteligibilidade cultural” (BUTLER, 2003, p.39).

Em geral, parte-se do pressuposto de que sexo é algo definido pela natureza, fundamentado no corpo orgânico, biológico e genético, e de que gênero é algo que se adquire por meio da cultura. Esta compreensão se baseia na percepção de que o sexo - homem ou mulher — é um dado natural, a-histórico, e de que o gênero é uma construção histórica e social. Esta tese, porém, por um lado determinista e por outro construtivista, restringe em muito a possibilidade de compreensão das subjetividades e das sexualidades.

\footnotetext{
${ }^{1}$ Para mais detalhes sobre o dispositivo ‘diferença sexual’ na cultura contemporânea, ver Arán, 2005.
} 
Este tipo de raciocínio já foi bastante problematizado por autores como Michel Foucault, e Judith Butler. Segundo Foucault, o dispositivo da sexualidade na modernidade só pode ser compreendido por meio dos mecanismos de poder e saber que lhes são intrínsecos. Assim, sexo é o resultado complexo de uma experiência histórica singular e não uma invariante passível de diversas manifestações. Desta forma, falar de sexualidade é também se referir à produção dos saberes que a constituem, aos sistemas de poder que regulam suas práticas e às formas pelas quais os indivíduos podem e devem se reconhecer como sujeitos sexuados (FOUCAULT, 1990, p.10). Em outras palavras, sexo - homem, mulher — não é um simples fato ou uma condição estática e sim "uma construção ideal forçosamente materializada através do tempo” (BUTLER, 2002, p.18). ${ }^{2}$

Antes, convivíamos mais livremente com a possibilidade da mistura dos sexos. Somente a partir do século XVII é que as teorias biológicas da sexualidade e as condições jurídicas impostas aos indivíduos conduziram pouco a pouco à refutação da idéia da mistura de dois sexos em um só corpo, e restringiram “a livre escolha dos indivíduos incertos" (FOUCAULT, 1993, p.116). O dispositivo de poder instaurou a necessidade de saber por meio da medicina qual o sexo determinado pela natureza e, por conseqüência, aquele que a justiça exige e reconhece. Assim, ser “sexuado” é estar submetido a um conjunto de regulações sociais, as quais constituem uma norma que, ao mesmo tempo em que norteia uma inteligibilidade e uma coerência entre sexo, gênero, prazeres e desejos, funciona como um princípio hermenêutico de auto-interpretação (BUTLER, 2003, p.142). Neste sentido, “o verdadeiro sexo" 3 é o efeito da naturalização de uma norma materializada.

Da mesma forma, gênero não é uma construção social imposta a uma matéria antes determinada (o sexo), e sim um efeito performático que possibilita a constituição e o reconhecimento de uma trajetória sexuada, a qual adquire estabilidade em função da repetição e da reiteração de normas. Assim, é importante pensar por meio de que normas reguladoras se materializam os sistemas sexo-gênero (BUTLER, 2002, p.18). Seguindo este raciocínio, os efeitos de gênero, ou mesmo de corpos, entendidos como produção de subjetividades, emergem na moderni-

\footnotetext{
2 É importante salientar que mesmo considerando a historicidade do sexual e o caráter normativo da materialização dos corpos, isso não significa que a produção discursiva compreenda a totalidade da matéria. "Corpos certamente vivem e morrem, ouvem e dormem, sentem dor e prazer, enfrentam doenças e violências, e esses 'fatos', poder-se-ia ceticamente declarar, não podem ser sumariamente tratados como construção. Deve certamente haver algum tipo de necessidade que acompanha estas experiências primárias e irrefutáveis. […] Pensar o corpo como constituído exige um repensar do significado de construção propriamente dita" (BUTLER, 2002, p.12).

3 "Precisamos verdadeiramente de um verdadeiro sexo"? é o título da Introdução do livro de Foucault sobre Herculine Barbin, um hermafrodita do século XIX (FOUCAULT, 1980).
} 
dade através da reiteração da matriz heterossexual constituída ao mesmo tempo pela dominação masculina e pela exclusão da homossexualidade. ${ }^{4}$

No entanto, se a produção repetida da normatização da sexualidade é necessária, isto significa que a materialização nunca é de fato completa, dado que os corpos nunca obedecem por completo às normas pelas quais sua materialidade é fabricada. Se os sistemas de sexo-gênero são construídos historicamente por meio de relações de poder, como ressalta Foucault e Butler, o gesto que instaura a norma produz também um domínio de corpos excluídos e abjetos, os quais servem de fronteira ou de limite de inteligibilidade. Várias manifestações das sexualidades são, desta forma, consideradas ininteligíveis, irreconhecíveis e inviáveis. A força da normatização se dá justamente pelo recalque, pelo repúdio ou mesmo pela foraclusão deste território que deve permanecer fora das possibilidades de simbolização.

Sabemos que a partir da instauração da norma heterossexual e reprodutiva deu-se a psiquiatrização do prazer perverso, o que fez com que a homossexualidade se tornasse o centro organizador do discurso sobre o desvio sexual (LANTERILAURA, 1994, p.42). Seguindo esta tradição, Krafft-Ebing, no século XIX, descreve todas as anomalias das "pulsões de reprodução da espécie" por meio da dicotomia estabelecida entre os pares norma/reprodução e esterilidade/doença (idem, p.38). Em Patologia geral: neurológica e psicológica, o autor apresenta um “esquema das neuroses sexuais" e define a sexualidade antipática como aquela que se caracteriza pela “total falta de sentimento pelo sexo oposto”. Segundo ele, os graus de manifestação desta patologia vão desde sentimentos e instintos homossexuais, passando por alterações da "personalidade psíquica”, com a correspondente "inversão sexual”, até o desejo de transformação corporal (SAADEH, 2004, p.38). Desde então, o transexualismo, derivado da psiquiatrização da homossexualidade, passa a ser descrito como uma patologia, e até hoje, como veremos a seguir, sua teorização sofre as influências desta origem genealógica.

\section{A SEXOLOGIA, A PSIQUIATRIA E O "TRANSTORNO DE IDENTIDADE DE GÊNERO"}

As primeiras cirurgias de transgenitalização foram realizadas por volta de 1920 na Alemanha e na Dinamarca. Tais procedimentos eram considerados como práticas de "adequação sexual", e associados ao tratamento de "pseudo-hermafroditas" e "hermafroditas verdadeiros". A primeira operação de que se tem notícia

\footnotetext{
${ }^{4}$ Segundo Laqueur (2001), a modernidade produziu o modelo dos dois sexos. A ciência aparece neste momento a serviço da cultura, com o objetivo de fundamentar a organização da sociedade - homem/público; mulher/privado - na natureza. Para isto, inventa-se uma nova forma de interpretar a diferença sexual: o modelo de dois sexos, o qual estabelece uma distinção ontológica e horizontal entre o masculino e o feminino.
} 
foi realizada em 1921 por Feliz Abraham, em “Rudolf”, considerado o primeiro transexual redefinido. Logo em seguida, o pintor Einar Wegener, em 1923, aos 40 anos, retirou os testículos e o pênis e se tornou Lili Elbe (CASTEL, 2001, p.85). Na Dinamarca também foram realizadas outras cirurgias bem sucedidas tal como a de Robert Cowuell, aviador da Segunda Guerra Mundial, que se tornou Roberta Cowuell, ainda que sem notoriedade e divulgação (SAADEH, 2004, p.200). Somente com a intervenção praticada por Christian Hamburger, em 1952, num jovem de 28 anos chamado George Jorgensen, ex-soldado do exército americano, este procedimento veio a público. A notoriedade do caso marcou uma nova forma de interpretação do fenômeno, provocando um enorme interesse por parte da sexologia, da endocrinologia, da urologia e da psiquiatria na pesquisa e no tratamento do transexualismo. ${ }^{5}$

Posteriormente, Harry Benjamin cria o conceito de transexualismo, com o qual se passa a teorizar e descrever o fenômeno transexual. ${ }^{6}$ Em 1966, este autor propõe uma escala de "orientação sexual”, inspirado nas classificações criadas ainda no século XIX por Krafft-Ebing, Hirschfeld e Ellis, a qual estabelece a um só tempo uma diferença entre travestismo e transexualismo, assim como a exclusão da homossexualidade, dado que os pacientes se definiram como heterossexuais. ${ }^{7}$

Um maior aprimoramento deste raciocínio tornou-se possível com a contribuição de John Money que passou a preconizar uma separação entre o "sexo real” — ancorado na biologia e na "natureza" - e o registro subjetivo do gênero, estabelecido por meio da educação e das influências culturais. Com o auxílio de estudos realizados com crianças, Money demonstra a independência radical entre a identidade de gênero e o sexo biológico, indicando que o transexualismo se caracterizaria justamente pela não adequação entre um e outro.

Adotando em parte esta trajetória teórica, o psiquiatra e psicanalista Robert Jesse Stoler (1992) dá continuidade a esta distinção e propõe a noção de "núcleo de identidade de gênero" como operador central da compreensão da experiência transexual. Este conceito designa o sentimento de ser homem ou mulher, estabelecido no segundo e terceiro anos de vida, e torna-se uma importante referência nas teorias sobre o transexualismo. De acordo com este ponto de vista, a definição de transexualismo se baseia em três principais aspectos: 1) um sentimento de identidade permanente — crença (no caso do transexualismo masculino)

\footnotetext{
${ }^{5}$ Segundo Chiland (2003, p.10), neste período, Hamburger teria recebido 465 cartas de pessoas que se identificaram com a história de George e demandaram tratamento.

${ }^{6}$ Contudo, foi Magnus Hirschefeld, sexólogo alemão, quem utilizou pela primeira vez a palavra "transexualismo" para se referir ao "transexualismo psíquico" ou "transexualismo da alma", em 1932 (CHILAND, 2003, p.5).

7 "Escala de Harry Benjamin de Orientação Sexual, Desorientação e Indecisão de Sexo e Gênero (Homens)", disponível em: www.genderpsychology.org.
} 
numa essência feminina sem ambigüidades (diferentemente do transvestismo, por exemplo); 2) uma relação com o pênis vivida “como horror” (não existindo nenhuma forma de investimento libidinal); e 3) uma especificidade na relação com a mãe (que o autor chama de "simbiose"). Considerando, no entanto, que a capacidade de integração social destas pessoas permanece intacta, Stoler ressalta que esta relação originária não pode ser considerada psicotizante. Apesar da referência ao transexualismo como uma "desordem" ou "patologia" e da enorme influência das teorias da diferença sexual dos séculos XVIII e XIX em sua definição de gênero (ARÁN, 2003), o trabalho de Stoler nos oferece sobretudo a descrição de uma experiência (que poderia ser interpretada de outra forma), e não propriamente a fundamentação de uma desordem. Neste sentido, considerando que o transexualismo não seria uma psicose, o tratamento preconizado pelo autor é a cirurgia de transgenitalização.

Com base nestas premissas, Norman Fisk, em 1973, fundamenta uma nosografia psiquiátrica para o transexualismo, ancorada fundamentalmente num autodiagnóstico. Com efeito, até hoje, o Manual Diagnóstico Estatístico de Doenças Mentais (DSM IV) considera que há dois componentes no “Transtorno de Identidade de Gênero” que devem estar presentes no diagnóstico:

"Deve haver evidências de uma forte e persistente identificação com o gênero oposto, que consiste do desejo de ser, ou a insistência do indivíduo de que ele é do sexo oposto (Critério A). Esta identificação com o gênero oposto não deve refletir um mero desejo de quaisquer vantagens culturais percebidas por ser do outro sexo. Também deve haver evidências de um desconforto persistente com o próprio sexo atribuído ou uma sensação de inadequação no papel de gênero deste sexo (Critério B). O diagnóstico não é feito se o indivíduo tem uma condição intersexual física concomitante (por ex., síndrome de insensibilidade aos andrógenos ou hiperplasia adrenal congênita) (Critério C). Para que este diagnóstico seja feito, deve haver evidências de sofrimento clinicamente significativo ou prejuízo no funcionamento social ou ocupacional ou em outras áreas importantes da vida do indivíduo (Critério D)."8

Nesta interpretação está implícita a idéia de que o sexo funda-se nos aspectos biológicos do indivíduo. No entanto, também se leva em conta a existência de um forte desejo de mudar de sexo - que supõe uma adequação cirúrgica a um sexo dito psicológico — e a existência de uma identidade de gênero que pretende traçar fronteiras entre o normal e o patológico (CORRÊA, 1998).

\footnotetext{
${ }^{8}$ Disponível em: http: //www.psiqweb.med.br/dsm.html. Acesso em 1/8/2005.
} 


\section{A PSICANÁLISE, 0 TRANSEXUALISMO \\ E A CLÍNICA ESTRUTURAL DAS PSICOSES}

Outro conjunto de trabalhos bastante citado no debate sobre este tema provém da tradição psicanalítica. Para a psicanálise, a sexualidade e principalmente a diferença sexual, são fenômenos complexos que definem formas de manifestação das subjetividades. Um marco decisivo nesta compreensão foram os Três ensaios para uma teoria sexual, escrito por Sigmund Freud, em 1905. Apesar de Freud não se referir especificamente à transexualidade neste texto, ele inaugura uma nova forma de pensar a relação entre pulsão sexual e cultura, que vai influenciar todas as teorias sobre sexualidade desde então. Para Freud, não existe necessariamente uma correspondência entre pulsão e objeto, já que este último adquire um caráter variável. Neste sentido, as possibilidades subjetivas se fazem de acordo com a contingência da experiência com o outro, a qual sempre será determinada pelos contextos históricos e sociais. Não vamos nos referir aqui à complexidade deste debate, mas apenas apontar que a partir desta elaboração, a psicanálise pode transitar por diversos caminhos, os quais, por um lado, permitiram uma subversão na compreensão do sexual, deslocando as sexualidades ditas perversas do campo da psiquiatria e, por outro, estabeleceram uma nova forma de normatização por meio do imperativo do modelo do Édipo e da castração (ARÁN, 2001; BIRMAN, 1999; PEIXOTO JR., 2004; NERI, 2005, TORT, 2005).

Hoje, é recorrente nos trabalhos sobre transexualismo a referência à psicanálise lacaniana, em especial, Henry Frignet (2002), M. Czermak (1986), Catherine Millot (1992), Joël Dor (1987), entre outros. Nestas teorias destaca-se a relação entre a transexualidade e a compreensão lógica e estrutural da psicose. Cabe salientar que o próprio Lacan teria tido a oportunidade de encontrar "Henry", em 1952, paciente transexual de Jean Delay, e constatar "a dificuldade de realizar uma psicoterapia com transexuais”, já que estes, segundo o autor, não a desejavam e não pareciam ter “conflitos psíquicos” (CASTEL, 2003, p.372).

Nesta época, o debate sobre transexualismo na teoria psicanalítica estava fortemente marcado pela interpretação freudiana do Caso Schreber (Freud, 1911/ 1994) que, em certa medida, tinha como referência a relação entre homossexualidade e paranóia. Lacan, em parte herdeiro desta tradição, mesmo considerando as diferenças entre o transexualismo e a compreensão psiquiátrica da psicose, argumenta que o discurso transexual estaria baseado na certeza delirante em relação à identidade, e no desejo incontornável de “mudar de sexo”. Neste sentido, não tendo o Édipo, o recalque e a falta como operadores organizativos, o transexualismo seria uma forma específica de psicose.

Henry Frignet, ao propor uma clínica estrutural do transexualismo, diferencia "transexuais verdadeiros" de "transexualistas". Tendo como base os registros da identidade sexual e da sexuação, o autor sugere que nos transexuais a identi- 
dade sexual estaria foracluída, o que os colocaria “fora (do) sexo”. 9 Já os transexualistas teriam a identidade sexual assegurada, permanecendo apenas um impasse quanto à sexuação (FRIGNET, 2000, p.15). Tomando como base a interpretação lacaniana da noção de identificação proposta por Freud, ${ }^{10}$ Frignet destaca a importância da identificação originária como um processo inaugural de aquisição da subjetividade, na qual são combinados tanto os processos de identificação como os de reconhecimento pelo pai. Nestes termos, a identificação que Freud chamava de "amor ao pai" é preconizada como reconhecimento do “Nome do Pai”: uma operação primária, indispensável à estruturação subjetiva, e que permitirá apreender tanto o registro imaginário, como o do real do corpo. De acordo com esta interpretação, é

“essa identificação real que o transexual recusa, e é esta diferença, para ele inacessível, que vai fazer retorno no real sob a forma de reivindicação de ser de outro sexo outro no imaginário e Outro no simbólico —, com a demanda de redesignação anatômica, no imaginário e no real, que lhe acompanha, e a demanda de modificação, visando - sem espera — o simbólico, desta vez no seu estado civil”. (FRIGNET, 1999, p.86)

Para estes autores, portanto, dada esta "foraclusão do nome do pai", os transexuais não se identificam com "uma mulher" propriamente dita, mas com “A mulher”, posição idealizada e vivida como plenitude. A observação clínica demonstraria que importa mais a aparência de "ser" mulher, do que a possibilidade de "ter" relações sexuais. Diferentemente da neurose e da perversão, os

\footnotetext{
${ }^{9}$ Hors sexe, traduzido para o português como Extrasexo é um ensaio sobre transexualismo escrito por Catherine Millot (1992).

${ }^{10}$ Segundo Taillandier, Lacan, no Seminário IX - A Identificação - distingue três tipos de identificações, tendo como referência a elaboração realizada por Freud no texto Psicologia das massas e análise do eu, 1920. “I. Primeira identificação por 'incorporação' - termo questionado por Lacan - com o Outro, a quem se demanda algo no apelo de amor. Consiste, ainda, em identificar-se com o Outro da 'necessidade'. Aqui os termos são equívocos: trata-se da mãe, como sugerem certos textos, ou do pai, seguindo a linha freudiana? Ou antes, se tratará da mãe na medida em que esta é portadora da metáfora paterna primordial? II. Segunda Identificação - que, em função dos impasses necessários do desejo, se faz por regressão - a um traço unário tomado do Outro do desejo considerado como objeto, vindo a identificação substituir-se à perda da Versagung ('frustração') necessária. III. Terceira Identificação imaginária, histérica, do desejo com o desejo do outro, com o qual só há identificação na medida em que se é portador da marca de um desejo insatisfeito..." (TAILLANDIER, 1994, p.18).

A partir de tal elaboração, Frignet afirma que esta identificação primária pode ser considerada real na medida que se refere a uma incorporação do pai definitivamente perdido, o qual retorna enquanto Falo. "O falo enquanto letra, objeto paterno por excelência, que o sujeito vai poder estabelecer, ou seja, aceitar, articular com o simbólico sua identidade sexual real, o reconhecimento do que lhe faz diferente no real..." (FRIGNET, 1999, p.86).
} 
transexuais não teriam acesso à castração dita simbólica, o que em última instância os aproximaria dos psicóticos.

A partir destas suposições, alguns destes psicanalistas são bastante reticentes em relação à realização da cirurgia. Outros, no entanto, destacam a importância que ela pode adquirir na organização subjetiva. Como afirma Contardo Calligaris, ao propor uma clínica diferencial das psicoses, no transexualsimo a cirurgia pode ser compreendida como um esforço de constituição de uma "metáfora delirante no real do corpo" (CALLIGARIS, 1989 p.38). Neste sentido a operação transexual pode vir a ser um substituto logrado da metáfora paterna neurótica, mas com uma mudança de registro. O que para o neurótico é a significação sexuada obtida na filiação simbólica torna-se, para o transexual, a sexuação obtida numa operação cirúrgica (idem).

Outra possibilidade teórica comumente mencionada ainda no campo da psicanálise é aquela que remete o transexualismo a um grupo de casos ditos limites, os quais se situam entre a neurose e a psicose, estados que poderiam ser considerados como uma "doença do narcisismo" (CHILAND, 2003). A linha geral destes trabalhos parte da hipótese da existência de uma relação de objeto "pré-genital" bem distinta da psicótica (ainda que muito diferente também da relação objetal neurótica) na qual a experiência edipiana permanece fragmentária e prescinde do recalque como recurso organizador. Assim, os limítrofes pertencem a um domínio muito menos rígido, bem menos sólido e definido do ponto de vista estrutural, necessitando eventualmente de um outro tipo de apoio subjetivo (GREEN, 1999).

Colette Chiland, uma das principais teóricas deste campo, relata a diversidade da experiência transexual na atualidade e destaca a importância da realização da psicoterapia psicanalítica com os transexuais que a desejarem, ressaltando a importância da realização de um apoio psicológico e existencial no processo psicanalítico. Segundo a autora, o reconhecimento desta condição pode oferecer um espaço de acolhimento que permita uma melhor organização assim como a ampliação das possibilidades subjetivas.

A partir desta breve cartografia da transexualidade na sexologia, na psiquiatria e na psicanálise podemos vislumbrar até que ponto o diagnóstico de transexualismo está ancorado num sistema de sexo e gênero que pretende estabelecer fronteiras e limites entre o inteligível e o impensável, ou melhor, entre normais e “anormais”. Assim, para que se possa compreender o primeiro domínio, é necessário esboçar o segundo, provocando uma operação de exclusão inclusiva constitutiva da própria norma. "O impensável está assim plenamente dentro da cultura, mas é plenamente excluído da cultura dominante" (BUTLER, 2003ª, p.117). Porém, cabe perguntar: apesar da complexidade desta problemática, quais as possibilidades de uma reflexão crítica no interior da clínica/ 
teoria psicanalítica que permita o descolamento da transexualidade deste território normativo de patologização?

\section{A SEXUAÇÃO COMO RESTRIÇÃO CONSTITUTIVA}

Percorrendo a literatura aqui relacionada, não é difícil perceber que a fixidez da lei estruturalista estabelece, por meio de uma matriz heterossexual, as posições consideradas legítimas. Todo o resto então, torna-se incompreensível caso não corresponda a este sistema binário hierárquico, e permanece como um excesso impossível de ser inscrito no âmbito simbólico. Desta forma, aquilo que é possível de ser simbolizado será estabelecido por uma operação violenta de exclusão.

Dada a violência dessa exclusão inclusiva, algumas questões se colocam: Como se constitui um corpo sexuado, ou mesmo um ego corporal, no que concerne ao estabelecimento de suas fronteiras, contornos e limites espaciais (a projeção de uma superfície ou a imagem especular)? Em que medida os conceitos de identificação e de sexuação na psicanálise estão de tal forma referidos a uma lei estabelecida a priori que acabam por fixar e restringir as manifestações das sexualidades a duas posições normativas: "masculino" e "feminino”?"11

“Deve haver uma ligação entre esse processo de ‘assunção’ de um sexo, a questão da identificação e os meios discursivos pelos quais o imperativo heterossexual capacita certas identificações de sexo e foraclui e/ou des-reconhece outras identificações." (BUTLER, 2002, p.19)

Se compreendermos a lei como uma estrutura anterior e transcendente às manifestações sociais, políticas e necessariamente históricas, o simbólico será apresentado como uma força que não poderá ser modificada e subvertida sem a ameaça da psicose. No entanto, se compreendermos a lei como algo que é vivido e constantemente reiterado de forma imanente às relações de poder, as possibilidades de modificação e subversão inclusive do simbólico, não necessariamente significarão uma ameaça à cultura e à civilização.

“Se o 'sexo' é assumido da mesma maneira que a lei é citada [...] então 'a lei do sexo' é repetidamente fortificada e idealizada como lei apenas até onde esta é reiterada como lei, produzida como lei [...]. Interpretando o significado de 'assunção' em Lacan como citação, a lei não mais é dada em uma forma fixa anterior a sua citação, e sim produzida através da citação...” (BUTLER, 2002, p.147)

\footnotetext{
${ }^{11}$ Para um comentário crítico sobre as fórmulas de sexuação ver Arán, 2003.
} 
Diante dos dispositivos da sexualidade tão bem definidos na modernidade por meio da naturalização de sistemas normativos de sexo-gênero, como também da naturalização do sujeito do desejo, a transexualidade será sempre excluída das possibilidades subjetivas consideradas normais e legítimas. É necessário, portanto, certo estremecimento destas fronteiras excessivamente rígidas e fixas — tais como as do simbólico e das estruturas de poder - para que a transexualidade possa habitar o mundo viável da sexuação e sair do espectro da abjeção, seja como transtorno de identidade de gênero, seja como psicose. Desse modo, estaremos mais livres para compreender as diversas formas de identificação e de subjetivação possíveis na transexualidade.

Não podemos estabelecer a priori que transexuais padecem de uma patologia ou são necessariamente, por uma questão de estrutura, psicóticos. A clínica psicanalítica nos ensina que, antes de tudo, devemos escutar e basicamente tentar acolher as diversas manifestações das subjetividades. Sabemos que estamos num território movediço, bastante complexo e que não devemos ceder de imediato ao apelo do imperativo tecnológico e científico que pretende capturar e modelar os corpos. Porém, mais do que nunca, não podemos — em nome de uma antiga forma de organização social, que alguns preferem chamar de Lei - impor de forma violenta um diagnóstico psiquiátrico ou realizar uma interpretação psicanalítica, apenas para manter o nosso horizonte simbólico intocável.

\section{A TRANSEXUALIDADE, A CLÍNICA E AS NOVAS FORMAS DE SUBJETIVAÇÃO}

Nas últimas décadas este tema tem adquirido cada vez mais importância, sobretudo em função da regulamentação de programas de assistência a pacientes transexuais nos serviços públicos de saúde, o que exige uma reflexão mais rigorosa sobre questões de ordem ética, bioética, jurídica e social. ${ }^{12}$ Seguindo uma tendência internacional, em novembro de 1997, o Conselho Federal de Medicina, por meio da Resolução 1482/97, aprovou a realização de cirurgia de transgenitalização nos hospitais públicos universitários do Brasil.

Esta resolução considera que a cirurgia de transgenitalização tem como motivo essencial uma “intenção de beneficência”, baseada em dois princípios: um deles, fundamentalmente terapêutico, diz respeito à "busca da integração entre o corpo e a identidade sexual psíquica do interessado"; o outro refere-se ao princípio de autonomia e justiça, ou seja, ao direito de dispor do próprio corpo e a não-discriminação no pleito à cirurgia. Em 2002, a Resolução 1652 do CFM revogou a Resolução 1482/97 que autoriza a cirurgia de transgenitalização a

\footnotetext{
${ }^{12}$ Ver documento proposto na $1^{\text {a }}$ Jornada sobre Transexualidade e Saúde: a assistência pública no Brasil: “Transexualidade e saúde pública no Brasil”, disponível em: http://www.ims.uerj.br/ transexualidadesaude/. Acesso em 10/11/2005.
} 
título experimental. A partir desta segunda Resolução, considerando o estágio atual de seleção e tratamento dos casos de transexualismo e o bom resultado estético funcional das neocolpovulvoplastias e/ou procedimentos complementares, fica resolvido que as cirurgias para adequação do fenótipo masculino para feminino poderão ser praticadas em hospitais públicos ou privados, independentemente da atividade de pesquisa. No caso da neofaloplastia e/ou procedimentos complementares, a realização se manteve condicionada à prática em hospitais universitários ou hospitais públicos adequados para a pesquisa. A confirmação do diagnóstico de transexualismo torna-se então condição do tratamento, sendo que a cirurgia só poderá ser realizada após acompanhamento psiquiátrico por, no mínimo, dois anos. A partir daquele ano, vários serviços interdisciplinares especializados começaram a ser organizados, motivados, principalmente, pela demanda de transexuais que procuraram o atendimento público após a divulgação desta resolução pela mídia.

Tendo como referência uma experiência clínica institucional realizada no Hospital Universitário da UFRJ, observamos que a transexualidade se caracteriza por uma condição de intenso sofrimento. Esta experiência decorre não apenas por uma percepção de não-pertencimento ao sexo dito biológico, mas sobretudo pela precariedade social proveniente da não-aceitação desta condição por parte da normatividade cultural vigente (ARÁN, ZAIDHAFT, MURTA, 2006).

Nesta conjuntura, o atendimento psiquiátrico para a confirmação do diagnóstico de transexualismo tem sido um dispositivo de cuidado e prudência para a realização da cirurgia. Algumas pessoas, a partir desta situação, escolhem realizar uma psicoterapia; outras comparecem apenas para confirmar o diagnóstico. No entanto, não nos sentimos confortáveis nesta situação, já que sabemos que este mesmo diagnóstico é também um vetor de patologização e de estigma, o qual muitas vezes acaba por atribuir uma patologia ao paciente sem problematizar as questões históricas, políticas e subjetivas a propósito da psiquiatrização da condição transexual. Além disso, fica claro que esta “condição transexual” não significa nenhuma "incapacidade mental”, sendo que a maioria das pessoas tem total condição de exercer a autonomia de decidir sobre o seu próprio corpo (CALIFA, 2003).

Do nosso ponto de vista, é fato que a certeza quanto ao pertencimento ao gênero oposto, a qual às vezes se expressa pela crença numa identidade fixa, se repete no cotidiano do atendimento a pacientes transexuais. Entretanto, esta mesma ilusão não difere muito da ilusão de uma essência "masculina" ou "feminina" nos homens e mulheres considerados "normais". É evidente que o acolhimento e o reconhecimento deste desejo ou desta crença, sem dúvida têm uma função terapêutica, para não dizer existencial. No entanto, a transexualidade não fixa uma única posição subjetiva. Talvez o mais importante, nestes casos, seja deslocar 
a manifestação social da transexualidade da necessidade de traduzi-la de imediato numa estrutura ou num modo de funcionamento específico, o que nos permitiria escapar da psiquiatrização ou mesmo da violência da interpretação psicanalítica (ARÁN, ZAIDHAFT, MURTA, 2006).

Porém, pelo fato de estas pessoas estarem constantemente confrontadas com várias questões de natureza existencial, se é que podemos nos expressar assim, sintomas considerados "narcísicos" ou "limítrofes” muitas vezes fazem parte desta configuração subjetiva por uma questão contingente. Porém, não podemos perder de vista em que contexto cultural e social estes sintomas aparecem, já que, na transexualidade, o risco de patologização de um problema social está sempre presente. Neste sentido, é importante um estudo mais aprofundado sobre o tema para que a psicoterapia, quando desejada e necessária, não fique capturada pela exigência institucional de confirmação de diagnóstico e nem pela indicação da cirurgia, mas que possa seguir trajetórias singulares de subjetivação, as quais permitam que a transexualidade possa ser vivida.

Recebido em 11/11/2005. Aprovado em 2/5/2006.

\section{REFERÊNCIAS}

ARÁN, M. (2001) “O avesso do avesso: Feminilidade e novas formas de subjetivação”. Tese (Doutorado em Saúde Coletiva). Instituto de Medicina Social da Uerj, Rio de Janeiro.

. (2003) "Os destinos da diferença sexual na cultura contemporânea”, in Revista Estudos Feministas. Florianópolis: CFH/CCE/UFSC, v. 11, n. 2, p.399-422.

. (2004) "Lacan e o feminino: algumas considerações críticas", in Natureza Humana. Revista Internacional de Filosofia e Práticas Psicoterápicas. São Paulo: Educ., v. 5, n. 2, p.293-328.

(2005) "Sexualidade e política na cultura contemporânea: as uniões homossexuais”, in Bioética, reprodução e gênero na sociedade contemporânea (org. LOYOLA, M. A.). Rio de Janeiro/ Brasília: Abep/Letras Livres. ARÁN, M.; ZAIDHAFT, S.; MURTA, D. (2006) “Transexualidade e saúde: análise de uma experiência clínica institucional”. (no prelo)

BENJAMIN, H. (1966) The transsexual phenomenon. New York: Julian Press.

BENTO, B. (2005) "Da transexualidade oficial às transexualidades", in Sexualidade e saberes: convenções e fronteiras (orgs. PISCITELLI, A.; GREGORI, M.; CARRARA, S.). Rio de Janeiro: Garamond.

BIRMAN, J. (1999) Cartografias do feminino. Rio de Janeiro: Editora 34.

BUTLER, J. (2002) Cuerpos que importan. Sobre los límites materials y discursivos del "sexo". Buenos Aires: Paidós. 
(2003) Problemas de gênero. Feminismo e subversão da identidade. Rio de Janeiro: Civilização Brasileira.

(2004) Undoing Gender. Nova York/Londres: Routledge.

CALIFA, A. (2003) Par Le Mouvement transgenre. Paris: Epel.

CALLIGARIS, C. (1989) Introdução a uma clínica diferencial das psicoses. Porto Alegre: Artes Médicas.

CHILAND, C. (1998) "Transvestism and transsexualism", in International Journal of Psychoanalyze, 79 (1), p.156-9.

(2000) "The psychoanalyst and the transsexual patient", in International Journal of Psychoanalyze, 81(1), p.21-35.

(2003) Le Transexulisme. Que sais-je? Paris: PUF.

CONSELHO FEDERAL DE MEDICINA 1482/97. Autoriza, a título experimental, a realização de cirurgia de transgenitalização do tipo neocolpovulvoplastia, neofaloplastia e ou procedimentos complementares sobre gônadas e caracteres sexuais secundários como tratamento dos casos de transexualismo. Diário Oficial da União 1997; 19 set.

1652/2002. Dispõe sobre a cirurgia de transgenitalização e revoga a Resolução CFM 1482/97. Diário Oficial da União 2002, 2 dez.

CASTEL, P.(2003) La métamorphose impensable. Essai sur le transsexualisme et l'identité personnelle. Paris: Galimard.

CORRÊA, M. (1998) "Sexo, sexualidade e diferença sexual no discurso médico: algumas reflexões", in A sexualidade nas ciências humanas (org. LOYOLA, M. A.). Rio de Janeiro: EdUerj, p.69-92.

CZERMARK, M. (1982). "Précisions sur la clinique du transsexualisme", in Le discours psychanalytique, n.3, p.16-22.

DOR, J. (1987) “Transexualisme et sexe des anges”, in Structure et Perversions. Paris: Denoël, p.235-56.

DSM (IV) Classificação Internacional das Doenças Psiquiátricas. Disponível em: http: //www.psiqweb.med.br/dsm.html. Acesso em: 1/8/ 2005.

ERIBON, D. (2003) Hérésies. Essais sur la théorie de la sexualité. Paris: Fayard.

FREUD, S. (1994) Obras completas. Buenos Aires: Amorrortu.

(1905) “Tres ensayos de teoría sexual”, v. VII, p.110-124.

(1920) "Psicología de las masas Y análisis del yo”, v. XVIII, p. 63-136.

FRIGNET, H. (1999) "Identité sexuelle et transexualisme”, in Logos et Anankè. Revue de Psychanalyse et de Psychopathologie, n.1, p.83-96. . (2000) O transexualismo. Rio de Janeiro: Companhia de Freud.

FOUCAULT, M. (1980) "Introdução", in Herculine Barbin: being the recently discovered memoirs of a nineteenth-century French hermaphrodite. Nova York: Pantheon Books.

\footnotetext{
(1993) História da sexualidade I. A vontade de saber. Rio de Janeiro: Graal. Graal.

(1988) História da sexualidade II. O uso dos prazeres. Rio de Janeiro:
}

FRAISSE, G. (1996) La différence des sexes. Paris: Presse Université de France. GREEN, A. (1999) Les états limites. Paris: PUF.

LAQUEUR, T. (2001) Inventando o sexo. Rio de Janeiro: Relume Dumará. 
LANTERI-LAURA, G. (1994) Leitura das perversões. Rio de Janeiro: Jorge Zahar Editor.

LOBATO, M.I. et al. (2001) “Transexualismo: uma revisão”, in Jornal Brasileiro de Psiquiatria, v. 50 (11-12), p.379-388.

NERI, R. (2005) A psicanálise e o feminino: Um horizonte da modernidade. Rio de Janeiro: Civilização Brasileira.

PEIXOTO JUNIOR, C. A. (2004) “A Lei do Desejo e o desejo produtivo: transgressão da ordem ou afirmação da diferença?”, in Physis. Revista de Saúde Coletiva, v.14, n.1, Rio de Janeiro: IMS/Uerj/Cepesc, p.109127.

SAADEH, A. (2004) "Transtorno de identidade sexual: um estudo psicopatológico de transexualismo masculino e feminino”. Tese (Doutorado em Ciências). Departamento de Psiquiatria da Faculdade de Medicina da USP.

STOLLER, R. J. (1969). Sex and gender. v.1. Nova York: Science House. . (1974) Sex and gender. Nova York: Aronson. (1992) A experiência transexual. Rio de Janeiro: Imago.

SCHREBER, D. P. (1984) Memórias de um doente dos nervos. Rio de Janeiro: Graal. TAILLANDIER, G. (1994) “A resenha do seminário A Identificação, de Lacan”, in As identificações na clínica e na teoria psicanalítica. Rio de Janeiro: Relume Dumará.

TORT, M. (2005) Fin du dogme paternal. Paris: Aubier.

“Transexualidade e saúde pública no Brasil”. Disponível em: http:// www.ims.uerj.br/transexualidadesaude

Márcia Arán

marciaaran@terra.com.br 